\title{
A UV-Spectrophotmetric Chemometric Method for the Simultaneous Determination of Sulfadoxine and Pyrimethamine in Tablets
}

\author{
Hagga M. A. Mohamed ${ }^{1}$, Mohd. Imran', Monadil H. M. Ali', Mohammed F. Abdelwahab' and \\ Abdullrahman A. Alhaj' \\ 'Faculty of Pharmacy, Northern Border University, Rafha, 91911, PO Box 840, Kingdom of Saudi Arabia; \\ mohamed.hagga@yahoo.com \\ ${ }^{2}$ KCMS, Khartoum, Sudan
}

\begin{abstract}
In the present study, a simple, inexpensive, precise and accurate UV-spectrophotometric method based on chemometrics, has been developed for the simultaneous determination of sulfadoxine and pyrimethamine in tablet formulation. The $\%$ recoveries obtained were $99.7 \% \pm 0.9 \%$ and $101.5 \% \pm 0.8 \%$ for sulfadoxine and pyrimethamine, respectively. The developed method has been compared to USP-HPLC method with regard to accuracy and precision. The calculated F-ratio and the $(\mathrm{t})$ statistics indicate that there is no significant difference at $5 \%$ level with regard to precision and accuracy between the proposed and the USP methods. Moreover, the developed method is simple, cost-effective, and less timeconsuming. Accordingly, it can be used advantageously in routine quality control of sulfadoxine and pyrimethamine in tablet formulation.
\end{abstract}

Keywords: Chemometrics, Pyrimethamine, Simultaneous Determination, Sulfadoxine, Tablets, UV

\section{Introduction}

Malaria, caused by plasmodium parasite, is the number one killer disease in many developing countries. It is endemic in tropical countries in Africa, Asia, and South America. The disease has an economic and social impact on the communities and its treatment is a priority. The natural alkaloid, quinine, extracted from Cinchona bark, was the first anti-malarial drug. In the present time, several synthetic anti-malarial drugs such as chloroquine, balaquine, mefloquine, mepacrine, and proguanil are administered separately or combined. By time the malarial parasite developed resistance rendering the majority of the synthetic anti-malarials in-effective. The search for a radical treatment of malaria is relentless and attempts to prepare vaccine were reported ${ }^{1}$.

Sulfadoxine (Figure 1), is chemically known as
4-amino-N- (5, 6-dimethoxy-4-pyrimidinyl) benzene sulfonamide. It is approved by the United States Food and Drug Administration for use as treatment and preventive measure against malaria ${ }^{2}$. It is an ultra-long-lasting sulfonamide often combined with pyrimethamine to treat or prevent malaria. However, due to its side effects, it is no longer recommended as a routine preventive measure ${ }^{3}$, but only to treat serious malarial infections or to prevent them in areas where other drugs may not work ${ }^{4}$.

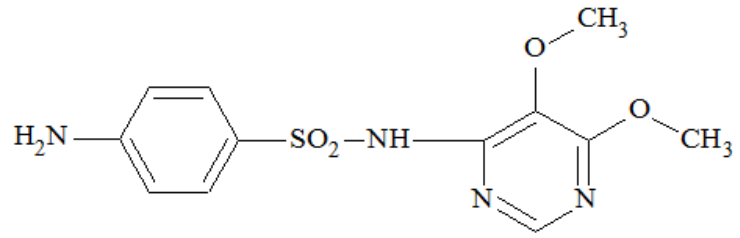

Molar Mass: 310.32

Figure 1. Molecular structure of Sulfadoxine.

* Author for correspondence 
Pyrimethamine (Figure 2) is known chemically as 5-(4-chlorophenyl)-6-ethyl-2,4-pyrimidine diamine. It is a medication used for protozoal infections and administered as an anti-malarial drug (4).

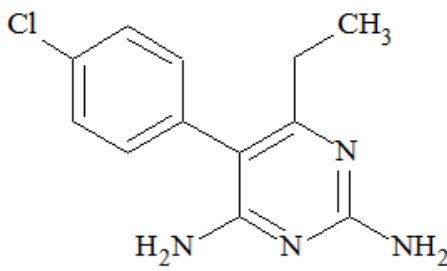

Molar Mass: 248.71

Figure 2. Molecular structure of Pyrimethamine.

Sulfadoxine and pyrimethamine combination is used in the treatment of acute, uncomplicated Plasmodium falcipram malaria for patients in whom chloroquine resistance is suspected. In addition, the combination may be recommended as a prophylaxis for travellers to areas where chloroquine resistant $P$. falcipram malaria is endemic or when alternative therapy is not available or is contraindicated. Under certain circumstances, the combination may also be used in toxoplasmosis cases ${ }^{5}$.

Sulfadoxine-pyrimethamine combination induces serious side effects including fever, increased sensitivity of skin to sunlight, soreness of the tongue and skin rashes ${ }^{3}$. Less common side effects are blood in urine or stool, chest pain, cough, loss of appetite, nausea, painful and difficult urination, yellow eyes and skin, and weakness ${ }^{3}$. Overdose causes severe bleeding and bruising, unsteadiness, and convulsion ${ }^{3}$.

To achieve desirable curative effect and lower toxicity, quality control of the content of each drug in the tablet formulation is crucial. Various UV, HPLC, and electrophoretic quantitative methods ${ }^{6-13}$ were reported for the estimation of sulfadoxine and pyrimethamine separately and combined with other drugs. The United States Pharmacopoeia (USP) adopts Reverse Phase High Performance Chromatography (RP-HPLC) for the simultaneous assay of sulfadoxine and pyrimethamine in tablets $^{14}$.

In this connection, it can be seen that within the last decade or so a number of publications have emerged in the literature dealing with the applications of UV-chemometric techniques ${ }^{15,16}$ to the simultaneous determination of individual drugs coexisting in mixtures. These techniques have now gained recognition in the quality control of drug mixture and pharmaceutical formulations containing two or more active ingredients with overlapping spectra without prior separation. $\operatorname{In}^{17-2}$ is indicated as notable examples.

In this work, a simple, accurate, precise, and inexpensive quantitative method has been developed for the simultaneous determination of the coexisting two drugs in tablet dosage form. The method is based on a chemometric procedure involving the inverse UVcalibration method without prior separation. Compared to HPLC, the developed chemometric UV-procedure proved to be adequately accurate and precise. Moreover, being simple and inexpensive, it is more appealing to use for routine assay of sulfadoxine-pyrimethamine combination in tablet than HPLC which is demanding in terms of running cost and sophistication.

\section{Experimental}

\subsection{Theoretical Considerations}

Binary mixtures of drugs with overlapping UV-spectra may be determined by zero order spectrophotometry when the overlapping does not obscure the existence of two distinctly separate absorption maxima. However, in case of substantial spectral overlapping, derivative UV-spectrophotmetry may be adopted successfully for the simultaneous analysis of the two components of the mixture. Furthermore, the spectral overlapping may be so severe such that derivative spectrophotometry is not capable to resolve the problem. In such situations, HPLC is the method of choice since this technique possesses the ability to separate the components and quantify each.

It is of interest to apply the inverse calibration method using UV-spectrophotometry for the simultaneous determination of sulfadoxine and pyrimethamine in tablet dosage form. The success of the attempt is rewarding as it means that a simple, inexpensive, and reliable UV-spectrophotometric method can be used for the simultaneous determination of sulfadoxine and pyrimethamine in tablet formulation.

The theoretical basis of the inverse calibration procedure $^{9}$ originated in equation (1).

$$
C=f(A)
$$

where concentration, is a function of absorbance, A. This is the inverse of classical method where $(\mathrm{A})$ is a 
function of $(\mathrm{C})$. For the binary mixture, two concentration variables are involved, namely, $\mathrm{C}_{1}$ and $\mathrm{C}_{2}$.

Generally the inverse calibration method can be implemented for a binary mixture as follows:

- Initially the UV-spectrum of each component is recorded and at least 5 wavelengths $\left(\lambda_{1}, \lambda_{2}, \lambda_{3}, \lambda_{4}\right.$, $\lambda_{5}$ ) selected in the overlapping zone for measuring absorbance, $A_{1}, A_{2}, A_{3}, A_{4}$, and $A_{5}$.

- About seven standard solutions are prepared containing known varying concentrations $\left(\mathrm{C}_{1}\right.$ and $\left.\mathrm{C}_{2}\right)$ of the pure components. The number of wavelengths selected should be greater than the number of components.

- The absorbance of each of the above solutions in (ii) is measured at $\lambda_{1}, \lambda_{2}, \lambda_{3}, \lambda_{4}$, and $\lambda_{5}$ to give correspondingly $\mathrm{A}_{1}, \mathrm{~A}_{2}, \mathrm{~A}_{3}, \mathrm{~A}_{4}$, and $\mathrm{A}_{5}$.

- The data of (iii) are processed by suitable software program such as Minitab 14 to give two calibration equations. The calibration equations (2 and 3 ) are worked out by multiple linear regressions based on the principles of least-squares.

$C_{1}=k_{1}+\alpha_{1} A_{1}+\alpha_{2} A_{2}+\alpha_{3} A_{3}+\alpha_{4} A_{4}+\alpha_{5} A_{5}$

$C_{2}=k_{2}+\beta_{1} A_{1+} \beta_{2} A_{2+} \beta_{3} A_{3+} \beta_{4} A_{4+} \beta_{5} A_{5}$

$\mathrm{C}_{1}$ and $\mathrm{C}_{2}$ are concentrations of the components of the binary mixture, $k_{1}$ and $k_{2}$ are constants, $\alpha_{i}$ and $\beta_{i}$ are coefficients. The constants and coefficients are worked out by the software program used.

- Similarly, solutions of the samples are treated by measuring absorbances, $A_{1}, A_{2}, A_{3}, A_{4}$, and $A_{5}$ at the corresponding wavelengths $\lambda_{1}, \lambda_{2}, \lambda_{3}, \lambda_{4}$, and $\lambda_{5}$.

- The measured absorbances of the samples are substituted in the calibration equations ( 2 and 3 ) to give $\mathrm{C}_{1}$ and $\mathrm{C}_{2}$.

- The content of each component in the tablet formulation is computed using $\mathrm{C}_{1}$ and $\mathrm{C}_{2}$.

\subsection{Materials}

Sulfadoxine reference substance was obtained from Control of Pharmaceutical and Biological Products, Beijin, China. Pyrimethamine reference standard was purchased from Lupin Pharmaceuticals, India. The pharmaceutical formulation of tablets containing sulfadoxinepyrimethamine was a gift from Amipharma, Khartoum,
North Sudan. Phenacitin donated by Khartoum Medical Supplies, Sudan was used as internal standard.

\subsection{Solvents}

HPLC grade methanol, and distilled water. Acetonitrile was obtained from Scharalau Chemie, Spain. Glacial acetic acid was analytical grade reagent obtained from Guangzhou Chemicals Reagent Factory, Guangzhou, China.

\subsection{Instrumentation}

Schimadzu Groups UV-Vis-Spectrophotometer model Mini 1240, made in Japan, was used in the spectrophotometric measurements.

For chromatography, Schimadzu High Performance Liquid Chromatograph, model Sol-10 AVP with a Variable UV-detector, made in Japan, and was used at ambient temperature. Stainless steel $\mathrm{C}_{18}$ column containing packing $\mathrm{L} 1$ and of dimensions $30 \mathrm{~cm} \times 3.9 \mathrm{~mm}$ (I.D.) was employed.

\subsection{UV-Spectra and the Calibration Equations}

About $0.5 \mathrm{~g}$ of sulfadoxine reference standard was accurately weighed and dissolved in $100 \mathrm{~mL}$ methanol. Similarly, a stock solution was prepared by dissolving about $0.025 \mathrm{~g}$ of pyrimethamine, accurately weighed, in $100 \mathrm{~mL}$ methanol. Separate dilute solutions were prepared from the stock solution for each drug and a binary mixture. The UV-spectra were recorded in the range $200-400 \mathrm{~nm}$ as shown in Figures (3 to 5).

\subsection{The Calibration Equations}

To obtain the two calibration equations, five wavelengths in the overlapping zones, namely, 291, 286, 276, 273, and $268 \mathrm{~nm}$ were selected for measurement of the absorbance $A_{1}, A_{2}, A_{3}, A_{4}$, and $A_{5}$ of the binary mixtures containing known varying concentrations of sulfadoxine and pyrimethamine. Absorbances of seven mixtures are assembled in Table 1.

The application of Minitab 14 software using the data in Table 1 gave the following calibration equations. 


$$
\begin{aligned}
& \mathrm{C}_{1}=1.47+42.4 \mathrm{~A}_{1}+21 \mathrm{~A}_{2}-15 \mathrm{~A}_{3}-316 \mathrm{~A}_{4}+318 \mathrm{~A}_{5} \\
& \mathrm{R}^{2}=99.9 \% \\
& \mathrm{C}_{2}=0.07+2.12 \mathrm{~A}_{1}+1.0 \mathrm{~A}_{2}-0.77 \mathrm{~A}_{3}-15.8 \mathrm{~A}_{4}+15.9 \mathrm{~A}_{5} \\
& \mathrm{R}^{2}=99.9 \%
\end{aligned}
$$

where $\mathrm{C}_{1}$ and $\mathrm{C}_{2}$ stand for the concentrations of sulfadoxine and pyrimethamine, respectively.

\subsection{Checking the Reliability of the Calibration Equations}

A series of synthetic binary mixtures of sulfadoxine and pyrimethamine reference standards were prepared and the amount of each recovered was found from the calibration equations (2 and 3) using $A_{1}, A_{2}, A_{3}, A_{4}$, and $\mathrm{A}_{5}$ absorbance (Table 2).

\subsection{Sample Preparations and Procedures}

Twenty tablets were weighed, powdered in a mortar, and the average weight of tablet was calculated. An amount of powder equivalent to one tablet was accurately weighed, transferred to a volumetric flask and dissolved in 100 $\mathrm{mL}$ methanol by mechanical stirring for 30 minutes. The mixture was filtered, and the filtrate was kept as a stock solution from which suitable dilutions were prepared to give absorbance $A_{1}, A_{2}, A_{3}, A_{4}$, and $A_{5}$ at the corresponding wavelengths, $\lambda_{1}, \lambda_{2}, \lambda_{3}, \lambda_{4}$, and $\lambda_{5}$. Table 3 shows the $\%$ recoveries of sulfadoxine and pyrimethamine in the tablet formulation.

\subsection{The USP HPLC Method}

\subsubsection{Mobile Phase}

Prepared by degassing and filtering a mixture of dilute glacial acetic acid (1 in 100) and acetonitrile (1:4 v/v).

\subsubsection{Stock Solution}

About $500 \mathrm{mg}$ of standard sulfadoxine and $25 \mathrm{mg}$ of standard pyrimethamine were accurately weighed, transferred to $100 \mathrm{~mL}$ volumetric flask and dissolved in about $35 \mathrm{~mL}$ acetonitrile. The volume was adjusted to 100 $\mathrm{mL}$ with the mobile phase.

\subsubsection{Standard Preparation 1}

Exactly $25 \mathrm{~mL}$ of the stock solution and $2 \mathrm{~mL}$ of the internal standard solution were transferred to $50 \mathrm{~mL}$ volumetric flask, adjusted to volume with the mobile phase and mixed.

\subsubsection{Standard Preparation 2}

Exactly $2 \mathrm{~mL}$ of the stock solution and $10 \mathrm{~mL}$ of the internal standard solution were transferred to $250 \mathrm{~mL}$ volumetric flask, adjusted to volume with the mobile phase and mixed.

\subsubsection{Assay Preparations}

From the remaining powder of the 20 tablets ground in the spectrophotometric part of this work, a sample equivalent to $500 \mathrm{mg}$ sulfadoxine and $25 \mathrm{mg}$ pyrimethamine was accurately weighed and transferred into $100 \mathrm{~mL}$ volumetric flask. About $35 \mathrm{~mL}$ of the acetonitrile was added, and the mixture was shaken for 30 minutes. The volume was adjusted to $100 \mathrm{~mL}$ with the mobile phase mixed, and filtered through $0.45 \mu \mathrm{m}$ membrane filter. Exactly $25 \mathrm{~mL}$ of the filtrate and $2 \mathrm{~mL}$ of the internal standard solution were transferred to $50 \mathrm{~mL}$ volumetric flask, adjusted to volume with the mobile phase and mixed to give assay preparation 1 .

For assay preparation 2,10 mL of the internal standard solution and $2 \mathrm{~mL}$ of the filterate were transferred into 250 $\mathrm{mL}$ volumetric flask, diluted to volume with the mobile phase and mixed.

\subsection{The Chromatographic System Optimization}

Five $10 \mu \mathrm{L}$ aliquots of the standard preparation and assay preparation were separately injected and the peak responses were recorded at $2 \mathrm{~mL} /$ minute flow rate. The relative standard deviation was less than $2.5 \%$, the resolution factor between the internal standard and sulfadoxine on one hand and pyrimethamine on the other hand was not less than 1.0. No interfering peaks by excipients of the formulation were observed (Figure 6).

\subsection{Procedure}

Equal volumes of $10 \mu \mathrm{L}$ of the standard preparation and assay preparation were separately injected into the chromatograph. From the peak responses obtained, the quantity (in mg) of sulfadoxine in the portion of tablet taken was calculated by the formula: 


\section{$12.5 \mathrm{C}\left(\mathrm{R}_{\mathrm{u}} / \mathrm{R}_{\mathrm{s}}\right)$}

where $\mathrm{C}$ is the concentration (in $\mu \mathrm{g} / \mathrm{mL}$ ) of standard sulfadoxine in the standard preparation 2 , and $\mathrm{R}_{\mathrm{u}}$ and $\mathrm{R}_{\mathrm{s}}$ are the relative peak response ratios obtained from assay preparation 2, and the standard preparation, respectively.

Similarly the quantity (in $\mathrm{mg}$ ) of pyrimethamine in the portion of tablets taken was calculated from the formula:

$0.2 \mathrm{C}\left(\mathrm{R}_{\mathrm{u}} / \mathrm{R}_{\mathrm{s}}\right)$

where $\mathrm{C}$ is the concentration (in $\mu \mathrm{g} / \mathrm{mL}$ ) of standard pyrimethamine in the standard preparation 1 , and $\mathrm{R}_{\mathrm{u}}$ and $\mathrm{R}_{\mathrm{s}}$ are the relative peak response ratios obtained from assay preparation 1 , and the standard preparation 1 , respectively.

Table 4 shows the comparison of the results obtained by the developed chemometric and the USP-HPLC methods.

\section{Results}

A UV-spectrophotmetric chemometric method for the simultaneous determination of sulfadoxine and pyrimethamine in tablets has been developed. Figure 3 and Figure 4 represent the ordinary UV-spectra of methanolic solutions of pure sulfadoxine and pyrimethamine with absorption maxima at $273 \mathrm{~nm}$ and $276 \mathrm{~nm}$, respectively.

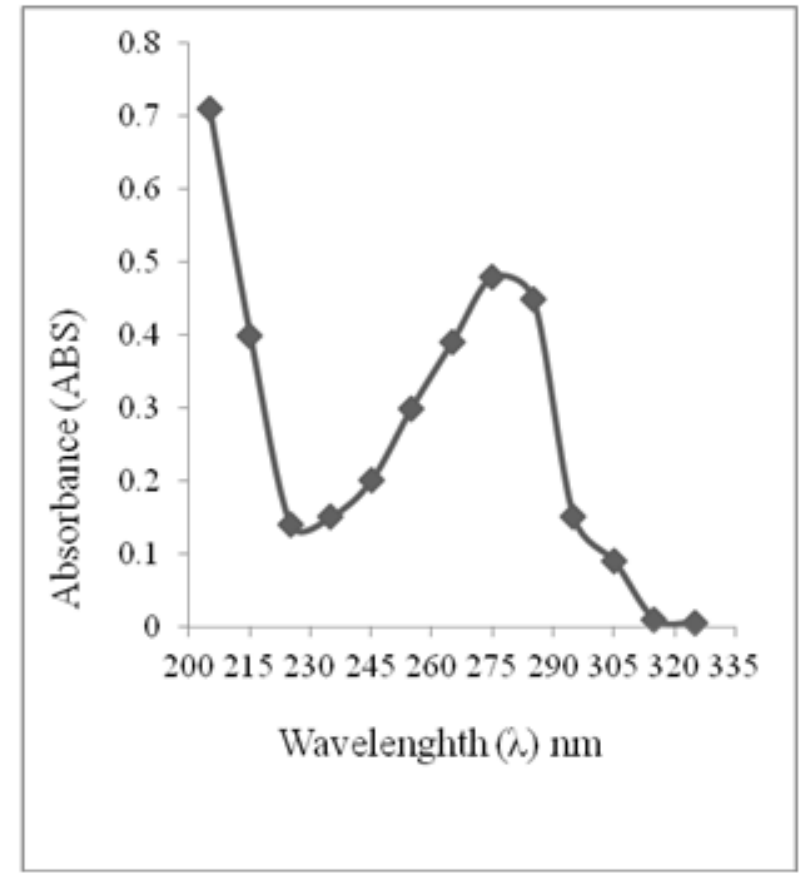

Figure 3. Zero order absorption spectrum of pure sulfadoxine $(10 \ldots)$.

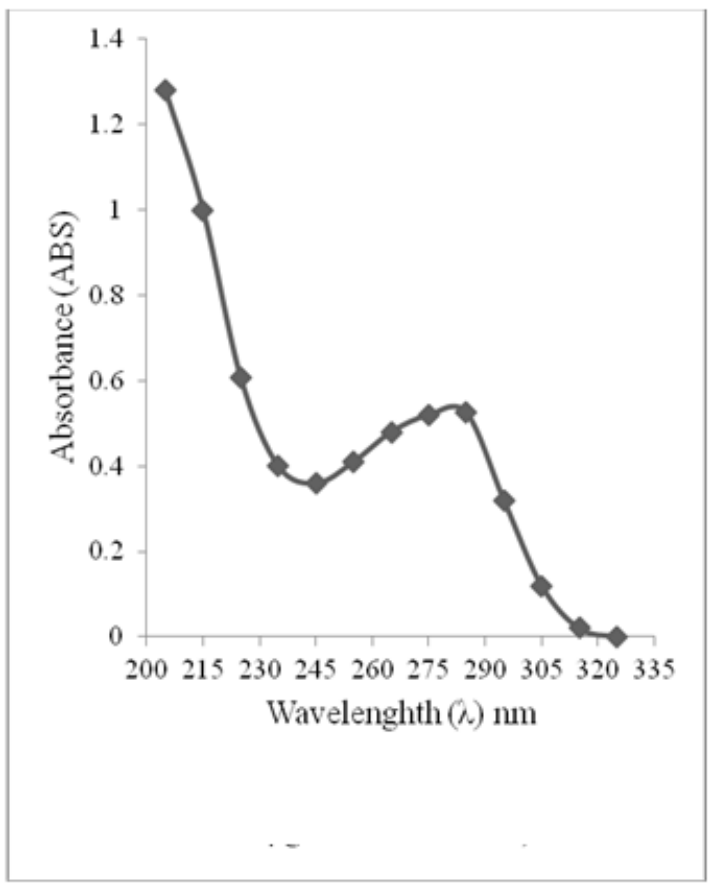

Figure 4. Zero order absorption spectrum of pure pyrimethamine $(1.0 \mu \mathrm{g} / \mathrm{mL}$ in methanol).

On the other hand Figure 5 depicts the UV-absorption spectrum of the binary mixture.

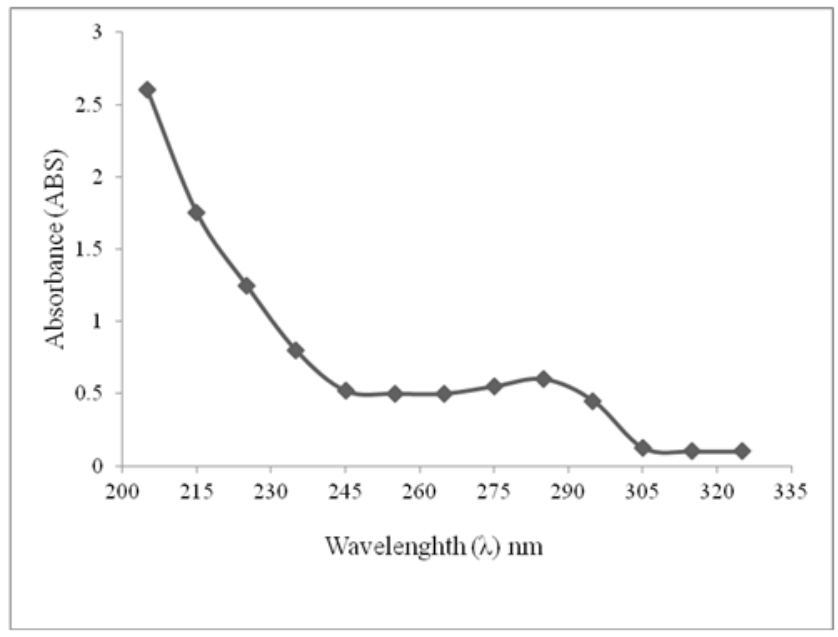

Figure 5. Zero order absorption spectrum of mixture of sulfadoxine and pyrimethamine.

The merger of Figure 3 and Figure 4 highlights the need for a selective analytical method for the simultaneous determination of the two components. The developed 
chemometric method can be advantageously applied to resolve the problem.

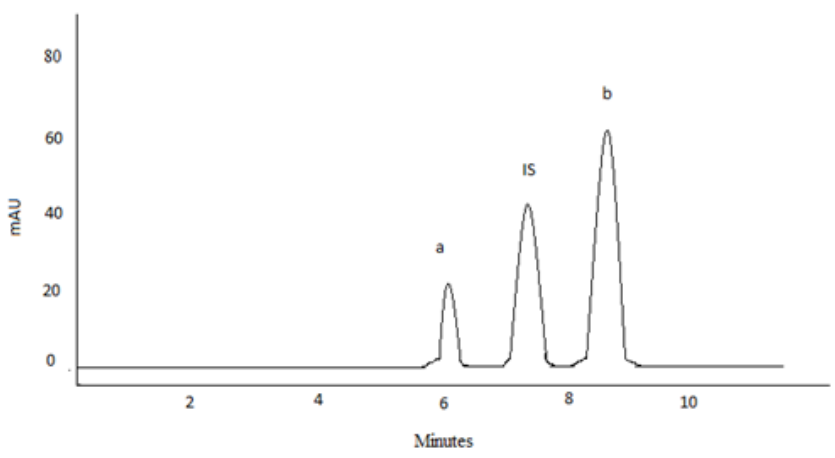

Figure 6. Representative chromatogram of Pyrimethamine (a) and Sulfadoxine (b) in the tablet extract in the presence of the internal Standard (IS).

Table 1 displays the absorbance values of seven synthetic mixtures used for computation of the constants and the coefficient of the calibration equations. The value of the coefficient of determinations $\left(\mathrm{R}^{2}=99.9 \%\right)$ suggests excellent linearity.
Table 1. Absorbance values ( $\mathrm{A}_{1}, \mathrm{~A}_{2}, \mathrm{~A}_{3}, \mathrm{~A}_{4}$, and $\left.\mathrm{A} 5\right)$ at $291,286,276,273$, and $268 \mathrm{~nm}$ for sulfadoxine and pyrimethamine binary mixtures

\begin{tabular}{ccccccc}
\hline $\begin{array}{c}\text { Sulfadox- } \\
\text { ine }\left(\mathrm{C}_{1}\right) \\
(\mu \mathrm{g} / \mathrm{mL})\end{array}$ & $\begin{array}{c}\text { Pyrimeth- } \\
\text { amine }\left(\mathrm{C}_{2}\right)\end{array}$ & $\mathrm{A}_{291}$ & $\mathrm{~A}_{286}$ & $\mathrm{~A}_{276}$ & $\mathrm{~A}_{273}$ & $\mathrm{~A}_{268}$ \\
\hline 10.0 & 0.50 & 0.382 & 0.449 & 0.659 & 0.667 & 0.640 \\
9.0 & 0.45 & 0.337 & 0.440 & 0.580 & 0.587 & 0.562 \\
8.0 & 0.40 & 0.313 & 0.408 & 0.539 & 0.545 & 0.521 \\
7.0 & 0.35 & 0.270 & 0.353 & 0.467 & 0.472 & 0.451 \\
6.0 & 0.30 & 0.233 & 0.306 & 0.404 & 0.409 & 0.390 \\
5.0 & 0.25 & 0.189 & 0.248 & 0.328 & 0.331 & 0.315 \\
4.0 & 0.20 & 0.149 & 0.195 & 0.259 & 0.262 & 0.248 \\
\hline
\end{tabular}

The data collected in Table 2 summarize the results obtained when checking the validity of the two calibrating equations. The \% recoveries of $99.7 \%$ and $99.4 \%$ and the RSD $\%$ of \pm 1.5 and \pm 3.2 reflect satisfactorily valid results.

Table 3 exhibits the \% recoveries obtained by applying the developed chemometric method to the simultaneous determination of sulfadoxine and pyrimethamine in tablet dosage form. The mean \% recoveries were $99.7 \%$

Table 2. Simultaneous determination of sulfadoxine and pyrimethamine in the binary synthetic mixtures using the inverse calibration method

\begin{tabular}{cccccc}
\hline $\begin{array}{c}\text { Sulfadoxine }(\mu \mathrm{g} / \\
\mathrm{mL})\end{array}$ & $\begin{array}{c}\text { Sulfadoxine re- } \\
\text { covered }(\mu \mathrm{g} / \mathrm{mL})\end{array}$ & \% Recovery & $\begin{array}{c}\text { Pyrimethamine }(\mu \mathrm{g} / \\
\mathrm{mL})\end{array}$ & $\begin{array}{c}\text { Pyrimethamine } \\
\text { recovered }(\mu \mathrm{g} / \mathrm{mL})\end{array}$ & \% Recovery \\
\hline 10.0 & 9.96 & 99.6 & 0.50 & 0.51 & 102.0 \\
9.0 & 8.86 & 98.4 & 0.45 & 0.46 & 102.2 \\
8.0 & 7.86 & 98.3 & 0.40 & 0.39 & 97.5 \\
7.0 & 6.86 & 98.0 & 0.35 & 0.36 & 102.9 \\
6.0 & 6.06 & 101.0 & 0.30 & 0.30 & 0.24 \\
5.0 & 5.06 & 101.2 & 0.25 & 0.19 & 96 \\
4.0 & 4.06 & 101.5 & 0.20 & \multicolumn{3}{c}{ Mean \% recovery $=99.4$} \\
\hline \multicolumn{5}{c}{ RSD\% $= \pm 3.2$} \\
\hline
\end{tabular}

Table 3. Values of $\%$ recoveries of sulfadoxine and pyrimethamine in tablet formulation

\begin{tabular}{cccccc}
\hline & Sulfadoxine & \multicolumn{3}{c}{ Pyrimethamine } \\
\hline $\begin{array}{c}\text { Claimed Sulfa- } \\
\text { doxine }(\mu \mathrm{g} / \mathrm{mL})\end{array}$ & $\begin{array}{c}\text { Found Sulfadox- } \\
\text { ine }(\mu \mathrm{g} / \mathrm{mL})\end{array}$ & \% Recovery & $\begin{array}{c}\text { Claimed Pyrimeth- } \\
\text { amine }(\mu \mathrm{g} / \mathrm{mL})\end{array}$ & $\begin{array}{c}\text { Found Pyrimeth- } \\
\text { amine }(\mu \mathrm{g} / \mathrm{mL})\end{array}$ & \% Recovery \\
\hline 10 & 9.97 & 99.7 & 0.50 & 0.52 & 104.0 \\
9 & 8.97 & 99.7 & 0.45 & 0.44 & 97.8 \\
8 & 7.87 & 98.4 & 0.40 & 0.39 & 97.5 \\
7 & 6.97 & 99.6 & 0.35 & 0.36 & 102.9 \\
6 & 5.98 & 99.7 & 0.30 & 0.31 & 103.3 \\
5 & 5.06 & 101.2 & 0.25 & 0.25 & 100.0 \\
4 & 3.97 & 99.3 & 0.20 & Mean \% recovery $=101.5$ \\
\end{tabular}


Table 4. Results of assay by the developed chemometric UV-Spectrophotometric and the USP-HPLC methods

\begin{tabular}{|c|c|c|c|}
\hline \multicolumn{2}{|c|}{ Developed Chemometric Method } & \multicolumn{2}{|c|}{ Developed Chemometric Method } \\
\hline \multicolumn{2}{|c|}{ (Sulfadoxine) } & \multicolumn{2}{|c|}{ (Pyrimethamine) } \\
\hline Claimed/Tablet & ${ }^{*}$ Found $(\mathrm{mg})$ & Claimed/Tablet & ${ }^{\star}$ Found $(\mathrm{mg})$ \\
\hline $500 \mathrm{mg}$ & $498.9 \pm 1.1$ & $25 \mathrm{mg}$ & $24.8 \pm 1.4$ \\
\hline \multicolumn{2}{|c|}{ USP-HPLC Method } & \multicolumn{2}{|c|}{ USP-HPLC Method } \\
\hline \multicolumn{2}{|c|}{ (Sulfadoxine) } & \multicolumn{2}{|c|}{ (Pyrimethamine) } \\
\hline Claimed/Tablet & ${ }^{\star}$ Found $(\mathrm{mg})$ & Claimed/Tablet & ${ }^{\star}$ Found $(\mathrm{mg})$ \\
\hline $500 \mathrm{mg}$ & $499.4 \pm 0.8$ & $25 \mathrm{mg}$ & $25.2 \pm 1.1$ \\
\hline \multicolumn{2}{|c|}{$\mathrm{t}_{\mathrm{cal}}=2.01 \mathrm{t}_{\text {crit }}=2.23(\alpha=0.05)$} & \multicolumn{2}{|c|}{$\mathrm{t}_{\text {cal }}=1.23 \mathrm{t}_{\text {crit }}=2.23(\alpha=0.05)$} \\
\hline \multicolumn{2}{|c|}{$\begin{array}{c}\mathrm{F}_{\text {cal }}=1.89 \mathrm{~F}_{\text {crit }}=5.05 \\
\mathrm{df}_{1}=\mathrm{df}_{2}=5(\alpha=0.05)\end{array}$} & \multicolumn{2}{|c|}{$\begin{array}{c}\mathrm{F}_{\text {cal }}=1.62 \mathrm{~F}_{\text {crit }}=5.05 \\
\mathrm{df}_{1}=\mathrm{df}_{2}=5(\alpha=0.05)\end{array}$} \\
\hline
\end{tabular}

and $101.5 \%$ with the corresponding $\%$ RSD of \pm 0.9 and \pm 0.8 for sulfadoxime and pyrimethamine, respectively.

The results assembled in Table 4 show the comparison of the developed chemometric and USP methods regarding accuracy and precision. The calculated $\mathrm{t}\left(\mathrm{t}_{\text {cal }}\right)$ and the $\mathrm{E}_{\text {ratio }}\left(\mathrm{F}_{\text {cal }}\right)$ at $5 \%$ level of significance are greater than the tabulated counter parts suggesting insignificant differences between the developed and the USP method.

\section{Discussion}

The UV-Spectra, Figure 3 to 5, of sulfadoxine and pyrimethamine exhibit severe overlapping with the absorption maxima too close, namely, $273 \mathrm{~nm}$ and 276 $\mathrm{nm}$. Under such circumstances ordinary and derivative spectrophotometric methods are not recommended for simultaneous determination of the two drugs since their spectra are irresolvable.

In such severe spectral overlapping, the inverse calibration method can be advantageously applied for the simultaneous determination of the two components.

Accordingly, absorbance of binary synthetic mixture of known varying concentration was measured for each mixture at the five selected wavelengths in the domain of spectral overlapping. Multiple linear regressions using Minitab 14 gave two calibration equations (4 and 5).

$$
\begin{aligned}
& \mathrm{C}_{1}=1.47+42.4 \mathrm{~A}_{1}+21 \mathrm{~A}_{2}-15 \mathrm{~A}_{3}-316 \mathrm{~A}_{4}+318 \mathrm{~A}_{5} \\
& \mathrm{R}^{2}=99.9 \% \\
& \mathrm{C}_{2}=0.07+2.12 \mathrm{~A}_{1}+1.0 \mathrm{~A}_{2}-0.77 \mathrm{~A}_{3}-15.8 \mathrm{~A}_{4}+15.9 \mathrm{~A}_{5} \\
& \mathrm{R}^{2}=99.9 \%
\end{aligned}
$$

where $\mathrm{C}_{1}$ and $\mathrm{C}_{2}$ stand for concentration (in $\mu \mathrm{g} / \mathrm{mL}$ ) of sulfadoxine and pyrimethamine, respectively, and $\mathrm{Ai}$ are the absorbances of the binary mixtures at the selected wavelengths. The coefficient of determination, $\mathrm{R}^{2}$, indicated excellent linearity. The results of the \% recovery in Table 2 proved the validity of the two calibration equations (4 and 5).

When the procedure was applied for the simultaneous assay of sulfadoxine and pyrimethamine in tablet dosage form, adequate $\%$ recoveries were obtained as shown in Table 3. Comparison of the results of the assay by employing the USP-HPLC and the developed Chemometric method was encouraging using the $t$-test for accuracy and the F-ratio test for precision.

\section{Conclusion and Recommendation}

A simple UV-spectrophotometric method based on chemometrics was developed for the simultaneous determination of sulfadoxine and pyrimethamine in tablet formulation. The proposed method succeeded in obtaining satisfactory $\%$ recoveries and standard deviation, namely, $99.7 \pm 0.9$ and $101.5 \pm 0.8$, for sulfadoxine and pyrimethamine, respectively. Statistical comparison of the recovery results by the developed method with those of the USP-HPLC method using the t-test and F-ratio showed no significant difference at 5\% level with regard to accuracy and precision. In addition, the developed method requires no prior separation for the determination of each of the two- co-existing drugs. It is to be noted that the tolerance range indicated by USP for the combined sulfadoxine and pyrimethamine is $90 \%$ 
to $110 \%$ in tablet formulation. As such the method is costeffective and can be used as a routine in the quality control of the combination of sulfadoxine and pyrimethamine in tablet formulation.

\section{References}

1. Angela KS, Jonathan MW, Jon KA, Clint P, Deborah A, Katherine T, Michael M. Perspective: Country ownership and gavi transition: comprehensive approaches to supporting new vaccine introduction. Health Aff. 2016; 35:2272-6.

2. Pyrimethamine, sulfadoxine and pyrithamine monograph for professionals. Drugs.com; 2014. Available from: http:// www.drugs.com/monograph/pyrimethamine-sulfadoxine-and-pyrimethamine.html

3. Pyrimethamine and sulfadoxine. Mayoclinic.com; 2016. Available from: http://www.mayoclinic.org/drugs-supplements/pyrimethamine-and-sulfadoxine-oral-route/description/drg-20062761

4. Fansidar, Pyrimethamine-sulfadoxine, (pyrimethamine/ sulfadoxine) dosing, indications, interactions, adverse effects and more. Medscape; 2016. Available from: http://reference.medscape.com/drug/fansidar-pyrimethamine-sulfadoxine-342694

5. Foot AB, Garin YJ, Ribaud P, Devergie A, Derouin F, Gluckman E. Prophylaxis of toxoplasmosis infection with pyrimethamine/sulfadoxine (Fansidar) in bone marrow transplant recipients. Bone Marrow Transplant. 1994; 14(2):241-5.

6. Saeed AM, Najma S, Farhan AS, Sajida N, Faiza Q. Simultaneous determination of pyrimethamine, sulfadoxine, mefloquin, and ibuprofen in pharmaceutical formulations by RP-HPLC. Med. Chem. Rese. 2010; 19(9):1043-54.

7. Amin NC, Blanchin MD, Ake M, Fabre H. Capillary zone electrophoresis as a potential technique for the simultaneous determination of sulfadoxine and pyrimethamine in tablet formulations. J Pharm Biomed Anal. 2012; 58:16871.

8. Timm U, Weidekam E. Determination of pyrimethamine in human plasma after administration of fansider-mefloquin by means of HPLC with fluorescence detection. J Chromatography. 1982; 230(1):107-14.

9. Tembhurkar NB, Chopade VV, Jadhav SB, Chaudhari PD. Development and validation of stability indicating assay method of pyrimethamine by using different stress conditions. Int J Pharm Sci Res. 2012; 3(8):2763-8.

10. Sharma S, Sharma MC. Determination of sulfadoxine in pharmaceutical formulations by dual wavelength spectrophotometry using methylene blue. Am Euras J Sci Res. 2011; 6(4):205-9.

11. Meena S, Sandhya SM. Validated HPTLC method for simultaneous analysis of pyrimethamine and sulfadoxine in pharmaceutical dosage forms. J Chem. 2013; 2013:698490.

12. Vemula VRB, Sharma PK, Singhvi I. HPLC method development and validation for simultaneous estimation of sulfadoxine and pyrimethamine in tablet dosage forms. Int J Pharm Sci. 2013; 3(4):295-8.

13. Meena S, Sandhya SM. Validated spectrophotometric methods for simultaneous analysis of pyrimethamine and sulfadoxine in pharmaceutical dosage forms. Asian J Pharm Clin Res. 2013; 6(Suppl. 3):121-3.

14. United States Pharmacopoeia, CD, 30, NF. Rockville: The USP convention; 2007.

15. Martens H, Nacs T. Multivariate calibration. New York: Wiley and Sons; 1989.

16. Beebe KR, Pell RJ, Seasholtz MB. Chemometrics: A practical Guide. 1982. New York: Wiley and Sons.

17. Khoshayand MR, Abdollahi H, Shariatpanahi M, Saadatfard A, Mohammadi A. Simultaneous spectrophotometric determination of paracetamol, ibuprofen and caffeine in pharmaceuticals by chemometric methods. Spectrochim Acta A Mol Biomol Spectrosc. 2008; 70(3):491-9.

18. Dinc E, Baleanu D, Onur F. Spectrophotometric multicomponent analysis of a mixture of metamizole, acetaminophen, and caffeine in pharmaceutical formulations by two chemometric techniques. J Pharm Biomed Anal. 2001; 26(5-6):949-57.

19. Dinc E, Baleanu D. Two new spectrophotometric approaches to the multicomponent analysis of acetaminophen and caffeine in tablets by least-squares and principal component regression. Il Farmaco. 2002; 57(1):33-7.

20. Madan J, Dwivedi AK, Singh S. Estimation of antitubercular drugs combination in pharmaceutical formulation using multivariate calibration. Anal Chim Acta. 2005; 538(12):345-53.

21. Hagga MAM, Monadil HMA, Nadir AMA, Sara AAM. Least-squares and inverse calibration chemometric spectrophotometric method for the determination of paracetamol-caffeine mixture in tablets. Indo Am J Pharm Res. 2014; 4(4):2146-52. 